\title{
Memórias incómodas e rasura do tempo: Movimentos estudantis e praxe académica no declínio do Estado Novo
}

Awkward Memories and Time Erasure: Student Movements and Traditional Student Codes ('Praxe Académica') in the Declining Years of the 'New State' Des mémoires gênantes et la rasure du temps: mouvements étudiants et codes étudiants traditionnels ("praxe académica") à la fin de l"Etat Nouveau"

\section{Miguel Cardina}

\section{OpenEdition}

\section{Journals}

Edição electrónica

URL: http://journals.openedition.org/rccs/654

DOI: $10.4000 /$ rccs.654

ISSN: 2182-7435

\section{Editora}

Centro de Estudos Sociais da Universidade de Coimbra

\section{Edição impressa}

Data de publição: 1 Junho 2008

Paginação: 111-131

ISSN: 0254-1106

\section{Refêrencia eletrónica}

Miguel Cardina, "Memórias incómodas e rasura do tempo: Movimentos estudantis e praxe académica no declínio do Estado Novo », Revista Crítica de Ciências Sociais [Online], 81 | 2008 colocado online no dia 01 outubro 2012, criado a 19 abril 2019. URL : http://journals.openedition.org/ rccs/654; DOI : 10.4000/rccs.654 


\section{MIGUEL CARDINA}

\section{Memórias incómodas e rasura do tempo: Movimentos estudantis e praxe académica no declínio do Estado Novo}

Apesar das repetidas evocações consagradas às lutas estudantis dos anos sessenta e setenta, persistem ainda lacunas e mal-entendidos que levam à manutenção de uma memória demasiado selectiva. O presente texto relaciona os movimentos estudantis desse período com as mutações então ocorridas no terreno da praxe académica em Coimbra, colocando em evidência o modo como durante cerca de dois decénios se foi construindo uma forma de estar e agir distante dos tópicos do tradicionalismo coimbrão e até mesmo em ruptura com ele. Simultaneamente, problematiza-se a imagem de um tempo contestatário focalizado quase exclusivamente na "crise de 69", chamando a atenção para algumas margens de esquecimento promovidas pela associação da memória dos combates estudantis dos "longos anos sessenta" a esse momento mais grandioso.

Muitas das narrativas respeitantes à chamada "praxe académica" exibem ainda frequentes distorções e apagamentos, parecendo mais dispostas a legitimar uma certa "identidade estudantil" do que a entender as dinâmicas complexas e conflituais que o objecto permite observar. A isto não é certamente alheia a dominância de um conceito totalizante de praxe, que tende a diluir o fenómeno no vasto, disperso e, por vezes, contraditório campo da vida escolar. ${ }^{1} \mathrm{Na}$ verdade, e apesar de constituída por uma multiplicidade mais ou menos fluida de rituais, simbologias e celebrações, a praxe distingue-se sobretudo pela capacidade de gerar linhas de demarcação e sinais de pertença a um espaço afectivo e geográfico comum. Ainda que a sua própria natureza evolua "à imagem da Universidade e da sociedade" (Frias, 2003: 82), ela, como nota Maria Eduarda Cruzeiro, não parece

\footnotetext{
${ }^{1}$ Em Coimbra, o carácter inoperativo deste conceito é visível na forma como certos territórios - algumas Repúblicas e organismos culturais, por exemplo - mantêm há décadas uma atitude de explícita afronta ou de proclamado alheamento em relação a comportamentos distintivos do universo académico mais tradicionalista, do qual se consideram exteriores (Estanque e Bebiano, 2007: 138-141).
} 
possuir uma elasticidade total. Enquanto "marca social distinta de pertença ao grupo", constituída por rituais de passagem visando tornar o ser "diferente e superior" (Cruzeiro, 1985-86: 23), vive necessariamente da (re)produção de elementos hierárquicos ("doutor"/ "caloiro" e "doutor"/"futrica") e punitivos (violências ritualizadas), traços que lhe são, de algum modo, genéticos e inapagáveis. ${ }^{2}$

Sendo uma reminiscência do tempo em que existia em Coimbra um "foro académico", o termo "praxe" apenas surgiu na segunda metade do século XIX - substituindo designações antigas como "investidas", "caçoadas" e "troças" - num contexto em que a hegemonia da Universidade de Coimbra começava a sentir-se ameaçada pelo aparecimento de novos pólos de ensino superior em Lisboa e no Porto (Cruzeiro, 1979). A sua existência foi mesmo, ao longo dos tempos, motivo de fortes condenações, tendo-se assistido a duas longas paragens durante o século XX (1910-1919 e 1969-1979). Apesar disso, são hegemónicas as leituras que falam de "costumes académicos que percorreram séculos e chegaram aos anos dias" (Nunes, 1996: 12), ou anúncios que descrevem a praxe como "fruto de uma vivência especial e diferente, gerada e desenvolvida em Coimbra ao longo de séculos e gerações" (Magnum Concilium Veteranorum, s.d.).

Marcadas por uma forte carga essencialista e mitográfica, estas exposições tendem a adequar-se àquilo que Richard Peterson (1992) designou de "fabricação da autenticidade" e a que, alguns anos antes, Eric Hobsbawm e Terence Ranger (1983) haviam chamado, num texto já clássico, "invenção da tradição". Debruçando-se sobre a ancestralidade ficcionada de alguns signos nacionais, estes historiadores demonstraram como as "tradições inventadas" se caracterizam por terem sido criadas num pretérito nem sempre longínquo, apesar de conservadas por meio da sua simulada colocação num locus inicial e hiper-significado. ${ }^{3}$ A manutenção desta presumível originalidade vai sendo garantida por uma panóplia de efemérides, lendas e símbolos que se encarregam de dar lugar à afirmação de uma ideia de continuidade histórica, aquilo a que Rouanet, na linha de Michel Foucault, chamou criticamente "desenrolar previsível do mesmo" (Rouanet, 1996: 111).

\footnotetext{
${ }_{2}^{2}$ Para uma abordagem da praxe enquanto fenómeno histórico, sociológico e antropológico, cf. Cruzeiro, 1990; Prata, 1993; Ribeiro, 2000; Frias, 2003; Nunes, 2004.

${ }^{3} \mathrm{Na}$ sua recente autobiografia, Eric Hobsbawm esclarece que os ensaios contidos em $A$ invenção da tradição foram bastante inspirados pela sua experiência de estudante em Cambridge nos anos 30, quando tudo parecia conduzir a um passado que "remontava ao século XII, embora algumas das suas expressões aparentemente mais entranhadas [...] tivessem na realidade sido forjadas havia apenas alguns anos" (Hobsbawm, 2005: 142).
} 
A análise que se segue não procura abordar os processos de naturalização associados ao fenómeno da praxe, nem se lança no questionamento das dinâmicas actuais - num contexto de massificação, regionalização e feminização do ensino superior - através das quais se vão (re)fazendo discursos sobre a "tradição académica". Pretende-se, isso sim, tomar em conta o percurso de dissidência política e cultural que atravessa os meios estudantis nos dois decénios finais do Estado Novo, mostrando de que modo o ambiente estudantil se reconfigurou então à luz de uma nova (auto-)imagem estudantil. Trata-se, em última análise, de seguir a recomendação de Walter Benjamin e "escovar a história a contrapelo", não tanto, neste caso, para "fazer saltar o continuum" do tempo (Benjamin, 1995: 79 e 84), mas apenas para mitigar algumas perplexidades voluntárias ou involuntárias ainda prevalecentes. ${ }^{4}$ Paralelamente, e com o mesmo intuito de construir um desenho mais completo desses anos, retrata-se o caminho seguido pela intervenção estudantil no troço final do regime, visando conferir-lhe uma inteligibilidade que ultrapasse a costumada crónica dos acontecimentos de 1969.

\section{Uma "tradição" em transformação}

$\mathrm{Na}$ curva da década de cinquenta para a década de sessenta do século XX, o ambiente académico coimbrão começa a afastar-se de certas formas tradicionais de integração estudantil. Este processo é indissociável da renovação política, cultural e moral que ocorre sobretudo a partir de 1956, ano em que se inicia a luta contra o "decreto 40.900", projecto-lei que procurava cercear a "autonomia" das associações de estudantes. A candidatura presidencial de Humberto Delgado, em 1958, tenderia a consolidar esta progressiva desafectação, tornando-se o terreno académico, cada vez mais, um foco de oposição ao regime. Em Coimbra, e acompanhando esta dinâmica de dissídio, assiste-se ao nascimento de grupos culturais que, de uma maneira ou de outra, se mostravam já distantes do diapasão do Estado Novo. Em 1954 é fundado o CELUC (Coral dos Estudantes de Letras da Universidade de Coimbra), que vem romper com a exclusividade do canto coral masculino protagonizado pelo Orfeon, assumindo uma postura mais arejada e até mesmo subversiva. Em 1956 são fundados mais dois grupos

\footnotetext{
${ }^{4}$ É comum encontrar-se um olhar desconhecedor ou displicente sobre os desenvolvimentos políticos, culturais e sociais ocorridos nos anos sessenta e setenta no meio estudantil coimbrão. No site da Direcção-Geral da Associação Académica de Coimbra (DG/AAC) fala-se do período imediatamente anterior à recuperação da Queima das Fitas, em 1980, como tendo sido marcado por "posições radicais [que] deram origem a confusões, ficando gerações sucessivas de estudantes privados de expandirem os seus anseios, especialmente consubstanciados na sua festa académica" (http://dg.aac.uc.pt/?section=submodule\&sub=display\&submodule_id=203).
} 
académicos: na senda do CELUC, nasce o CMUC (Coro Misto da Universidade de Coimbra) e, no mesmo ano, o CITAC (Círculo de Iniciação Teatral da Academia de Coimbra), que envereda por um percurso de experimentalismo e arrojo estético na prática teatral. Em 1958, aparece ainda o CAPC (Círculo de Artes Plásticas de Coimbra), destinado ao tratamento da arte contemporânea.

Entretanto, e ao mesmo tempo em que se assiste à cristalização normativa dos ritos e simbologias da "praxe" coimbrã, com a aprovação do Código da Praxe Académica de Coimbra (Andrade e Barros, 1957), uma série de artigos e cartas em jornais nacionais abre um debate em torno da praxe, que se estenderia mais tarde à discussão sobre os limites legítimos da intervenção política estudantil. A polémica inicia-se com um editorial de O Século, no qual, analisando-se a evolução das "recepções ao caloiro", se vaticina que "não tardarão a desaparecer por completo esses restos antipáticos de épocas distantes em que se negava à mocidade académica o direito de entrar pela primeira vez numa escola sem ser vaiada e, frequentes vezes, desalmadamente agredida" (S, 1957, 27171).

Pouco tempo depois o debate chegaria às páginas do Diário de Lisboa, com a discussão entre defensores e detractores da praxe a prolongar-se a um ritmo quase diário durante cerca de um mês. Do lado dos críticos, Fernando de Castro Saraiva ataca a praxe por assentar num conceito "estático" de tradição, por erguer a ideia da "antiguidade como critério de verdade", e por se fundar numa lógica invertida do mérito, que confere "mais categoria aos mais estúpidos e mais madraços" (DL, 1957, 12580). Todavia, uma boa parte das tomadas de posição vinha focar a relação umbilical entre Coimbra e a sua tradição académica: "Coimbra sem tradição não se entende nem se justifica. Coimbra é a própria tradição". Na opinião de Carlos Ganho, a praxe favoreceria "o à-vontade, o auto-domínio, o espírito de iniciativa [...] o senso de humor, a argúcia e, é claro, a resignação" (DL, 1957, 12584).

Em Dezembro de 1957, os estudantes apreciam em Assembleia Magna as "críticas feitas à praxe académica pela imprensa", condenando o ataque "às tradições" (AM, Livro de Actas 1955-1960, 12-1957). No jornal República, a DG/AAC considera a praxe "assunto da exclusiva competência dos estudantes de Coimbra [...] e só a eles cabe (se o entenderem!) actualizá-la, equilibradamente, e longe de qualquer especulação demagógica” (R, 1958, 9718). A revista Via Latina assume posição idêntica, ao mesmo tempo que censura a Rua Larga, revista dos antigos estudantes, por dar guarida a um texto crítico da praxe (VL, 1957, 76). Pouco tempo depois, Flávio Vara publica o opúsculo O espantalho da "praxe" coimbrã, 
no qual repudia o seu carácter de obrigatoriedade e sugere a actuação das autoridades para que se "impedisse que se cometessem muitas violências e indignidades com a máscara de brincadeiras de estudantes" (Vara, 1958: 79). A investida ocasionou pronta resposta dos sectores tradicionalistas, com Flávio Vara a ser declarado "futrica" pelo Conselho de Veteranos e a ver registada uma vigorosa réplica da parte de Mário Saraiva de Andrade (1959), um dos autores do Código da Praxe.

Em 1959, alguns textos aparecidos nas páginas da Via Latina prolongariam o debate, centrando-o agora na questão da validade e alcance da intervenção política estudantil. Enquanto para os sectores mais conservadores o associativismo deveria manter um vertente fundamentalmente recreativa, centrado no desporto universitário e na reprodução de uma legada mundivisão praxista, as "esquerdas" apostam numa concepção "solidária" da praxe, articulada com um associativismo de timbre reivindicativo. No fundo, eram duas noções distintas de "política" que se encontravam em jogo. Com base num conceito demonizado, Jasmins Pereira defende que "as associações académicas só podem realizar eficazmente os seus objectivos desde que se resguardem de quaisquer desvios políticos" (VL, 1959, 97). A mesma concepção é também defendida pelo então presidente da DG/AAC, Manuel Henrique Mesquita, que declara como indispensável "nunca dentro da A.A. haver actuação política” (VL, 1959, 97). À esquerda, procura-se desmistificar o sentido negativo do conceito de "política" de forma a possibilitar o alargamento dos âmbitos da intervenção estudantil. Para Jorge Araújo, "os problemas dos estudantes não podem abstrair-se do conjunto dos problemas nacionais" pelo que as associações de estudantes devem tomar posições políticas, "isentas de todo o partidarismo (e aqui nos parece residir a base de muitas confusões), [mas] assentes em princípios fundamentais de reivindicação" (VL, 1959, 89).

Em 1960, a DG/AAC é conquistada por uma lista de esquerda apresentada pelo Conselho de Repúblicas ${ }^{5}$, que introduz uma série de alterações qualitativas no discurso associativo, ao mesmo tempo que abre caminho ao afloramento de temáticas de cariz social, cuja face mais visível seria o importante conflito que então deflagra acerca do papel da mulher

\footnotetext{
${ }^{5}$ O Conselho de Repúblicas foi fundado a 11 de Dezembro de 1948. Estrutura assembleária que congregava todas as repúblicas de Coimbra, o CR teve uma importância capital como pólo dinamizador de um novo tipo de intervenção estudantil. Entre 1960 e 1965 (altura em que o governo nomeia uma Comissão Administrativa que, sucessivamente renovada, foi gerindo os destinos da AAC até 1968/69) e em 1969, todas as Direcções-Gerais eleitas partiram de listas conjuntas entre CR e Organismos Autónomos da AAC.
} 
na sociedade (Garrido, 1996: 77-118; Bebiano e Silva, 2004). O momento mais marcante deste debate seria a publicação da Carta a uma Jovem Portuguesa, assinada por um anónimo A., e posteriormente reivindicada por Artur Marinha de Campos. Nela, o autor escreve a uma genérica "jovem portuguesa", mostrando-se perturbado com a sua situação social, marcada por um "determinismo" que a obriga a viver do "lado de lá desse muro: o mundo inquietante da sombra e da repressão mental", mencionando, a terminar, "a concretização sexual do amor" (VL, 1961, 130). Os efeitos da Carta ultrapassaram o circunscrito perímetro da academia, provocando uma onda de indignação por parte das faixas mais conservadoras, que viam no texto "um ataque frontal à religião cristã e à Moral que está nos fundamentos da nossa sociedade" ("Frente a Frente", AAVV, 09-05-61).

Esta confrontação acaba por se inserir no debate em torno da validade do "convívio" entre elementos dos dois sexos e de academias diferentes, que vinha há algum tempo a ser levantado em Coimbra. Considerado como o meio "indispensável para se tomar consciência do formar de uma geração, dos passos a avançar, da mensagem a transmitir ao seu mundo" (AB, 1959, 45), a noção de "convívio" mais não era do que a reivindicação simultânea de uma maior abertura moral e da adopção tácita da perspectiva sindicalista. Na prática, sentiam-se já os efeitos da emergência de uma nova definição do estudante como "jovem trabalhador intelectual" que suplantou a sua imagem tradicional como "situado fora da sociedade, vivendo como uma espécie de parasita, passando a maior parte do seu tempo em ocupações agradáveis mais ou menos folclóricas e sem preocupações com o futuro" (Gaudez, 1965: 20).

A progressiva substituição do corporativismo pelo sindicalismo, com a consequente adesão a modos de pensar e agir mais empenhados socialmente, fez-se também através da transfiguração de algumas formas de exercício praxista. $\mathrm{Na}$ Latada de 1961/62, por exemplo, empunharam-se cartazes humorísticos de evidente alcance contestatário, como "o Tó [Salazar] tem um cancro. Coitado do cancro", ou "Angola é nossa" transportada por um estudante negro, como chega a noticiar com indignação o jornal nacionalista Agora (AG, 1961, 42). Organismos centrais da

\footnotetext{
${ }^{6}$ Esta definição programática deu corpo ao "sindicalismo estudantil", que tem na "Carta de Grenoble", aprovada em 1946 em congresso da UNEF (Union National des Étudiants Françaises), o seu documento fundador. Nela se estipulavam uma série de direitos e deveres do estudante, que o vinham entender como um elemento inserido na sociedade e com um papel na sua transformação e melhoria. Durante a década de cinquenta e sessenta, o "sindicalismo estudantil" tornou-se uma perspectiva bastante presente nos diferentes meios académicos, sobretudo europeus.
} 
"sociedade tradicional coimbrã" (Lopes, 1982), como o Conselho de Veteranos e o Conselho de Repúblicas, assumem lugar de destaque no oposicionismo académico, utilizando o poder de que dispunham como arma de intervenção política: decretus de suspensão da praxe, luto académico e cessação da Queima das Fitas passam a integrar os contextos de luta.

A utilização dos rituais e da simbologia praxista permitia que a contestação se inserisse no fluxo das vivências tradicionais coimbrãs, o que não só lhes conferia legitimidade como despertava uma certa complacência por parte da elite dirigente nacional, para quem Coimbra era ainda, simultaneamente, o lugar de um certo espírito corporativo, boémio e romântico e uma instituição universitária produtora dos cérebros do regime. No fado de Coimbra introduzem-se letras com preocupações sociais e políticas, em contraste com a dolência e o lirismo então característicos. Nesta linha, José Afonso gravará, em 1963, os primeiros exemplos da "canção de protesto": Os Vampiros e Menino do Bairro Negro. É também por esta altura que surge um tema, urdido no calor da "crise de 62", que seria utilizado como uma espécie de hino da intransigência estudantil: a Trova do Vento que Passa, de Adriano Correia de Oliveira e Manuel Alegre (Raposo, 2000).

Em 1962, é como resposta aos estímulos repressivos do governo que deflagra um conflito de dimensões consideráveis que levaria à demissão do reitor da Universidade de Lisboa, Marcelo Caetano, e à prisão e suspensão de numerosos estudantes de Coimbra e de Lisboa. No essencial, este período marca o afastamento de uma parte significativa da juventude universitária relativamente a um regime pouco dado a gestos de flexibilidade, ao mesmo tempo que permitiu a consolidação da perspectiva sindicalista no interior do movimento (Caiado, 1990: 71-116). Curiosamente, um inquérito levado a cabo em 1964 pela JUC (Juventude Universitária Católica) conclui que apenas uma pequena minoria $(5,4 \%)$ concorda com a posição da lei portuguesa que restringe a representatividade das associações estudantis aos sócios. No capítulo dos objectivos, três quartos dos inquiridos são de opinião que as associações devem "cuidar de todos os problemas dos estudantes" e não apenas concentrar-se nos "problemas escolares" $(10,2 \%)$ ou conduzir especialmente a sua atenção para os "problemas do país e do mundo" (7,2\%) (Situação..., 1967: 86-89). Ainda que no inquérito não se refira de modo explícito o termo "sindicalismo", Sousa Franco, numa análise efectuada na revista Estudos em 1967, considera que estes resultados apontam para a preponderância de uma "tendência sindicalista moderada" (E, 1967, s.n.) 


\section{Contestação estudantil no final dos anos sessenta}

No final dos anos sessenta, um conjunto variado de causas vem acelerar o processo de dissidência política e cultural dos meios estudantis. Em primeiro lugar, a recepção, ainda que intermitente e filtrada, de um generalizado caldo de rebeldia juvenil que eclodia um pouco por todo o mundo, e que contribuiu para a difusão de novas atitudes no campo da política, da moral e das sociabilidades. Mau grado a repressão política, a extensão aos vários domínios de uma moral conservadora de raiz católica e o fraco desenvolvimento urbano, ${ }^{7}$ o certo é que, progressivamente, o meio estudantil se foi mostrando permeável ao húmus de radicalismo e rebeldia típico daqueles "anos utópicos" (Mellor e Gervereau, 1997).

Em segundo lugar, registe-se a intromissão cada vez maior de uma retórica anti-regime, preocupada com a abordagem das questões sociais e apostada em romper a imagem do conjunto estudantil como corporação ensimesmada. Saliente-se, a este respeito, o efeito provocado pelo encontro, na sequência da participação nas acções de auxílio às vítimas das graves inundações ocorridas no Sul do país a 25 e 26 de Novembro de 1967, com uma população a viver em pobreza acentuada e que o regime abandonara à sua sorte, pouco intervindo nas acções de socorro que os bombeiros e os estudantes iam procurando realizar no terreno.

Por último, aponte-se também a crescente impopularidade das guerras coloniais, que cada vez mais iam significando, para os jovens, um escolho inamovível destinado a hipotecar-lhes o futuro. Iniciadas em Fevereiro de 1961, em Angola, e progressivamente alastradas a outros territórios - Guiné, em Janeiro de 1963 e Moçambique, em Agosto de 1964 - as guerras que o Estado português travou contra os movimentos independentistas africanos foram espalhando um gradual sentimento de repulsa na juventude universitária. No entanto, e até ao final da década, a centralidade da questão permaneceu circunscrita no terreno estudantil a alguns núcleos com ligações às colónias, como a Casa dos Estudantes do Império, as Repúblicas coimbrãs Kimbo dos Sobas e Mil-Y-Onários, ou a grupos mais combativos ligados à então embrionária extrema-esquerda.

Quando se chega a 1969, uma parte considerável da juventude encontrava-se já afastada das coordenadas ideológicas do regime, ao mesmo tempo que estabelecia aproximações aos mais variados matizes do mar-

\footnotetext{
7 Tanto Adérito Sedas Nunes como Hermínio Martins - respectivamente em 1964 e 1971 - referiram o carácter "dual" da sociedade portuguesa da época, com uma fraca classe média, uma escassa mobilidade social (Martins, 2006: 99-131) e marcada pela permanência conjunta e conflitual de valores, atitudes e comportamentos modernos e tradicionais (Nunes, 2000: 25-84).
} 
xismo. Nesta medida, a "crise de 69" representou uma transição na tipologia dos movimentos estudantis: se, nos anos anteriores, as bandeiras agitadas giraram em torno da defesa das "liberdades associativas", em 1969, a "democratização do ensino" caminhou a par com a "democratização das estruturas sócio-económicas". Em suma, e como se afirmava em Maio desse ano, "a nossa luta só poderá fazer tréguas quando tivermos atingido uma Universidade Nova num Portugal Novo" "Carta à Nação", DG, 07-05-69). Apesar disso, a agitação anticolonial mantinha-se ainda de fora do corpo explícito das reivindicações.

De Novembro de 1968 a Julho de 1969 assistiu-se a uma fase ascendente da luta, centrada, em traços genéricos, em redor de dois eixos. Em primeiro lugar, a preocupação em adoptar um discurso politizado, que visava transformar a contestação académica em contestação pedagógica e ideológica - a luta por uma "Universidade Nova" como um elemento indissociável da luta por uma "Sociedade Nova". Em segundo lugar, a definição de linhas tácticas que procurassem congregar a maioria dos estudantes, evitando o isolamento da vanguarda do movimento. Esta estratégia consubstanciou-se na ideia de que o trabalho fundamental deveria ser realizado nos cursos, com a eleição de delegados e a difusão de reivindicações de carácter essencialmente pedagógico, o que permitiu que o embate de 69 adquirisse um carácter cultural e de massas. Por outro lado, este cuidado em manter unida uma ampla base estudantil, levou a que o movimento se baseasse numa concepção legalista da luta, na recusa de uma confrontação directa com o poder, no entendimento da DG/AAC como direcção do movimento, e na canalização de rituais e símbolos ligados à "tradição académica" para o terreno da conflitualidade (Cruzeiro, 1989; Namorado, 1989).

Assim, e no essencial, o sucesso da "crise de 69" compreende-se pela conjugação de formas reivindicativas novas e sintonizadas com o "espírito do tempo", com o aproveitamento, em sentido progressista, de um certo ethos coimbrão. Se, por um lado, se utilizou a Queima das Fitas e o Luto Académico, cuja convocação reforçava política e simbolicamente a luta e levava à identificação de camadas estudantis mais conservadoras com o corpo das reivindicações, por outro, a "Operação Flor" (distribuição de flores na Baixa de Coimbra), a "Operação Balão" (largada de balões no Largo da Portagem), a adopção de tácticas "filo-guerrilheiristas" de embate com as autoridades ou a elaboração de cartoons humorísticos, são exemplos de novas formas de acção que entroncam em modalidades de contestação emergentes, nas quais as componentes política, cultural e geracional se combinavam. 


\section{Evocações e esquecimentos}

Não se podem pensar os processos de construção das memórias estudantis sem se ter em conta a particular instabilidade dos estudantes enquanto grupo social. $O$ facto de os estudantes do ensino superior serem indivíduos em trânsito, permanecendo, em regra, meia dúzia de anos no terreno universitário, faz com que a transmissão da memória tenha de lidar regularmente com interrupções e curto-circuitos, fenómeno que já foi mencionado como um dos seus traços mais persistentes (Boren, 2001). Se, por vezes, esta condição pode funcionar como potenciadora de um envolvimento mais criativo e descomplexado - porque menos subsidiário do peso das referências do passado -, muitas vezes o desconhecimento do lastro histórico pode dificultar a adopção de perspectivas mais distanciadas e reflexivas. A disponibilidade para experimentar os campos do possível - potenciada pela relativa independência da tutela paternal, pela relação ténue ou nula com o mercado de trabalho e pela curiosidade física e intelectual - conduz assim os estudantes a uma vivência centrada na novidade e algo despreocupada com os potenciais legados da memória, reduzida a alguns símbolos, observados num misto de admiração e negligência interpretativa.

A referência constante às "crises académicas" é um exemplo que ilustra bem esta situação. Nos mais diversos campos institucionais, a evocação das lutas estudantis concentra-se quase sempre na rememoração dos acontecimentos de 1962 e 1969, acompanhados, cada um deles, de uma respectiva circunscrição espacial: 1962 seria o ano da "crise" lisboeta, 1969 seria a data da "crise" coimbrã. ${ }^{8}$ Neste último caso, as sucessivas DG/AAC têm insistido em celebrar o acontecimento de variadas formas, com a edição de álbuns fotográficos e de brochuras, a colocação de placas comemorativas ou a realização de sessões com os intervenientes, geralmente realizadas a 17 de Abril. A importância do legado de 69 é tão presente que sempre que existem picos de contestação é comum a comparação com esse momento, integrando a iniciativa do presente numa espécie de legitimidade ética que teria o seu momento mais marcante naquele episódio. A este propósito, Ana Drago, no seu importante estudo sobre o movimento "antipropinas", refere a presença de uma "memória romantizada" que fornecia uma "imagem de heroicidade da condição de estudante" (Drago, 2004: 181). Deste modo, na primeira metade da década de 1990, num período "quente", eram muito comuns as referên-

\footnotetext{
${ }^{8}$ Isto apesar de os estudos existentes sobre ambos os acontecimentos mostrarem que os conflitos eclodiram em ambas as cidades e se inseriram num fluxo reivindicativo que transcendeu, a montante e a jusante, os referidos anos (Garrido, 1996; Duarte, 1997).
} 
cias a 1969 - "em '69 fizemos tremer o regime/em '94 fomos milhares a dizer NÃO!/Em '69 apanhámos porrada!/Em '94 quiseram-nos calar!”, dizia-se num documento datado de 1995 (ibidem: 180) - reenvios que funcionavam como instrumento de mobilização colectiva e como inspiração para o envolvimento pessoal. ${ }^{9}$

Esta exemplaridade encontra amplificação em alguns discursos de antigos activistas de 1969, que difundem, explicita ou implicitamente, a ideia de que aquele foi o momento por excelência, quase único, de contestação estudantil ao regime. Tenha-se em conta, porém, que muitos, como anota Fátima Saraiva, apenas voltaram a rememorar a "crise", "quando começaram as comemorações, dez ou quinze anos depois" (Cruzeiro e Bebiano, 2006: 208). Foi, de facto, a partir de meados da década de 1980 que se começou a divulgar uma arrumação narrativa baseada numa certa "memória de vitória". Esta viria a assentar na valorização do papel da unidade em detrimento da divergência ideológica, na análise das linhas políticas do movimento em lugar da consideração das componentes culturais e de costumes, mais espontâneas e menos tácticas, e na acentuação de um certo "imaginário de festa", necessariamente feliz, em vez de um olhar menos romântico, que contemplasse também o peso das experiências de cárcere, as ressacas, os desânimos e os caminhos distintos que o movimento estudantil trilhou no seguimento da "crise de 69".

Em alguns depoimentos mais recentes, alguns antigos estudantes sentem mesmo necessidade de atenuar uma certa mistificação efectuada em torno da "crise". Definindo-a como uma "boa nostalgia", Fernando Martinho fala, contudo, de "uma bolha" feita com uma "relativamente grande inconsistência e com uma adesão bastante epidérmica, emocional, romântica", tendo o cuidado de salientar que a "crença e adesão" a valores de resistência ao regime "é anterior e posterior à crise" (ibidem: 85). Como sublinha Luís Januário, "o movimento era uma caldeira com grupos mais avançados e grupos mais atrasados" (ibidem: 287), que se distinguiam tanto pelo grau de consciência política e pelos objectivos propostos para a luta estudantil, como pela linguagem usada ou pelas opções estéticas e culturais.

\footnotetext{
9 Jorge Correia, um antigo dirigente estudantil da década de 1990, refere-o deste modo: "Eu a primeira vez que entrei no edifício da Associação Académica, tive um arrepio, porque estava no sítio onde as coisas tinham acontecido. A primeira vez que eu entro no jardim da Associação, a imagem que eu tenho é das fotografias das Assembleias Magnas, a primeira vez que eu vou ao edifício das Matemáticas a primeira imagem que eu tenho é do 17 de Abril de $69 . .$. e há aqui um conjunto de pessoas que têm muito esta saudade bacoca de tempos não vividos e isso claramente influenciou." (Drago, 2004: 166-167). Sobre as representações das lutas estudantis dos anos sessenta no actual meio estudantil coimbrão, cf. Estanque e Bebiano, 2007: 169-176.
} 
Por outro lado, a inegável força simbólica de 69 leva a que, ainda hoje, estudantes que se remetiam a uma posição de distanciamento ou de efectiva recusa do movimento, tenham dificuldades em assumir-se como pertencentes à minoritária direita académica, produzindo declarações, no mínimo, desconcertantes. Em entrevista concedida em 2006, Souto Moura admite que furou a greve aos exames, que o seu grupo de amigos se centrava nos sectores da direita mais radicalizada, mas que se considerava "de esquerda" e adepto de uma democracia de tipo sueco. Nas suas palavras, estava equidistante quer dos simpatizantes do regime, quer "dos maoístas" - caricaturando deste modo o activismo da época, já que o advento organizado do maoísmo em Coimbra é posterior a 1969 (T, 2006, 3). De modo semelhante deve ser lida a presença de José Miguel Júdice na comemoração dos 35 anos da "crise académica de 69", organizada em 2004 pela DG/AAC, definindo-a na altura como uma revolta geracional, nessa medida também sua. ${ }^{10} \mathrm{Em}$ ambos os casos, a pertença ao campo afectivo da "crise" confunde-se com a estadia num domínio etário e geográfico comum, numa estratégia de naturalização/neutralização que visa esbater a importância das clivagens políticas, culturais e morais traçadas à época.

Registe-se ainda um fenómeno colateral provocado pela menção persistente à "crise de 69", e que consiste na rasura dos acontecimentos ocorridos nos anos imediatamente subsequentes. Um sintoma disso mesmo aparece na opção cronológica que preside ao conjunto de artigos sobre os movimentos estudantis durante a Ditadura Militar e o Estado Novo, coordenados por Maria Cândida Proença (1999), que, ao encerrar com um texto sobre 1969, deixa implicitamente cair um manto de silêncio sobre a agitação ocorrida posterior. Procurando contrariar um pouco este apagamento, uma das personagens de $O$ cão andaluz, o último romance de Jorge Seabra, fala daqueles momentos como "empolgantes e únicos", mas que não devem levar a que se ignore o período sucessivo, "estranhamente esquecido" (Seabra, 2007: 133).

Isto ajuda a explicar o modo como se inaugurou, em 2002, quase sem controvérsia ${ }^{11}$ um anfiteatro no Departamento de Física com o nome de Veiga Simão, antigo ministro da Educação de Marcelo Caetano, porventura mais hábil na gestão dos conflitos com o meio estudantil e conotado com os sectores "liberais", mas que não deixou de ser um ministro bas-

\footnotetext{
${ }^{10}$ Debate sobre os "35 anos da crise académica de 69", organizado pela DG/AAC e decorrido no Auditório da Faculdade de Economia da Universidade de Coimbra, a 17 de Abril de 2004.

${ }^{11}$ Apesar da opção das autoridades académicas e do silêncio dos organismos estudantis, a placa sinalizadora do anfiteatro foi roubada logo a seguir à inauguração, ao que tudo indica por um conjunto de estudantes que deste modo tomaram posição sobre o assunto.
} 
tante criticado. A sua titularidade na pasta coincide com o encerramento compulsivo das associações, com a colocação nas faculdades dos chamados "gorilas" - corpo de intervenção incumbido de disciplinar as escolas e com várias situações de disparos sobre estudantes, chegando, em Outubro de 1972, em Lisboa, a vitimar Ribeiro dos Santos e a ferir José Lamego e, dois anos antes, em Coimbra, a atingir gravemente no abdómen Fernando Seiça.

É de notar, pois, que a "crise de 69" não determinou um desfecho do conflito entre estudantes e autoridades. Entre 1970 e 1974, detecta-se um "outro período crítico", marcado pela inovação no plano dos conteúdos e da forma da intervenção estudantil. A consolidação de uma imagem de estudante modelada em função do seu "comprometimento social" originou a afirmação de canais de contestação explicitamente vocacionados para a recusa radical do regime político vigente (Cardina, 2008).

\section{Nova imagem do estudante e abandono da praxe académica}

A intervenção estudantil de natureza colectiva agrupou-se historicamente de acordo com três tendências: a) afirmação de formas de oposição às atitudes discricionárias ou a determinadas orientações das autoridades académicas; b) intervenção no sentido de promover alterações na política governamental para o sector educativo; c) envolvimento em iniciativas visando intervir nas transformações operadas na sociedade portuguesa e na definição do próprio regime (Bebiano, 2003). Esta terceira tendência, que se foi consolidando ao longo dos anos sessenta, assume clara hegemonia na configuração dos discursos e práticas estudantis no troço temporal que vai de 1969/70 a 1974. A leitura politizada das novas intenções governativas para o sector da educação - a conhecida "reforma Veiga Simão" - bem como o alastramento de uma postura anticolonialista e anticapitalista são disso exemplo.

A radicalização dos conteúdos da contestação deriva, em muito, da emergência de uma miríade de pequenos grupos de extrema-esquerda, fortemente radicados no meio estudantil, e que vêm introduzir novos referenciais éticos e estéticos provenientes da revolução cultural chinesa, da revolução cubana ou das generalizadas lutas estudantis. Assumindo uma pose de enfrentamento profundo dos Estados Unidos da América e do Ocidente capitalista, muitos destes novos ícones, como Mao ou Che Guevara, encarnam um "voluntarismo fundamentalmente anti-realista" que se alarga à própria recusa ideológica, política e cultural da norma soviética (Frank, 2000: 36).

O discurso esquerdista emergente apontava para a necessidade de se afrontar com radicalidade os métodos e a função da escola capitalista, 
bem como as organizações tradicionalmente enraizadas no meio estudantil, compostas por "burocratas completamente afastados das massas que dizem representar" ("Por um sindicalismo de tipo novo", Núcleos Sindicais, 04-72). O PCP, antes apelidado de "aventureirista" por querer forçar o confronto com as autoridades, via agora a sua organização para o meio estudantil, a UEC (União dos Estudantes Comunistas), classificada como "reformista", por preferir as temáticas de índole associativo em lugar do questionamento da sociedade capitalista.

Este novo quadro, conjugado com a forte repressão que então se abate sobre as estruturas associativas, ${ }^{12}$ leva a mudanças na forma de actuação estudantil. O movimento associativo, baseado em estruturas mais ou menos fixas e assente em princípios de reivindicação girando em torno da autonomia e da liberdade, é substituído por modos de contestação mais fragmentados, voluntaristas e radicalizados. Sem os espartilhos da representação, os meetings, os debates e os grupos de estudo passam a fazer parte da nova metodologia de acção. O confronto com o poder irrompe também fora dos delimitados recintos universitários, por meio de práticas mais ousadas como a distribuições temerárias de panfletos, o apedrejamento de instituições bancárias ou as manifestações-relâmpago contra a guerra colonial.

A definição dos estudantes como actores sociais em "compromisso com as forças revolucionárias" ("Em defesa de uma imprensa livre", CR, 1972, 3) leva à emergência de uma nova imagem do dirigente associativo, afastada já do modelo do representante "iluminado" ou mais "capaz" de entre as massas, para dar agora lugar ao estudante porventura mais anónimo mas que, dotado de uma igual capacidade reivindicativa, elegia e se fazia eleger. Em Coimbra, e ainda antes do encerramento da AAC, em Fevereiro de 1971, a constituição da lista única apresentada a sufrágio, em Abril de 1970, é exemplo desse alastramento de formas menos filtradas e mais directas de participação, tendência reconfirmada nas eleições de Novembro de 1970. As listas associativas "patrocinadas pelos caciques e aglutinando-se à volta de personalidades 'pardas'” são substituídas por métodos de democracia directa, onde "o nome dos estudantes é indicado desde as reuniões de curso, passando pelas de faculdade, até à AM" e o

\footnotetext{
${ }^{12}$ No início do ano lectivo de 1972/73 quase todas as associações de estudantes estão encerradas ou por legalizar. No Porto, a AE de Medicina encontra-se encerrada e as Comissões Pró-Associações de Economia, Engenharia, Letras, Liceus e Industrial estão por legalizar; em Lisboa as AE de Direito, Industrial e Ciências estão encerradas e as Comissões Pró-Associações estão por legalizar em Medicina e Farmácia e encerradas em Letras e Comercial; em Coimbra, a DG/AAC encontra-se encerrada desde Fevereiro de 1971 (s.t., Comissão Associativa, 16-11-72).
} 
próprio programa "construído na mais ampla discussão e participação massiva" ("Ao Trabalho, Ciências", s.a., 10-70).

Dão-se, ao mesmo tempo, importantes variações nas vivências estudantis. A incapacidade de harmonizar os fundamentos de um discurso fortemente politizado com práticas que, por atenuadas que fossem, dificilmente deixavam de ser elitistas em relação ao exterior e hierárquicas no seu interior, leva a que, após o luto académico de 1969, a praxe apareça posta em causa com maior profundidade, eliminando-se resquícios que, mesmo que não contivessem já o lado punitivo e hierárquico de outrora, mantinham ainda um timbre paternalista ou "iniciático". $\mathrm{Na}$ abertura do ano lectivo de 1970/71, consolidando o corte com a "retrógrada e tradicional perspectiva de integração praxística" "Semana da Recepção aos Novos Alunos”, DG, 12-11-70), a DG promove uma iniciativa na qual, em vez da "inferiorização despersonalizante", se aposta numa série de "colóquios e debates sobre os problemas actuais do estudante e da sociedade portuguesa" (ibidem). Nesse mesmo ano, o próprio Conselho de Veteranos trata de abolir o "rapanço", como é então noticiado na revista Capa e Batina (CB, 1970, 35).

Um outro sinal desta alteração ocorre no âmbito das Repúblicas. Se, em 1948, a carta constitutiva do CR declarava que estas se encontravam "unidas pela praxe" e que a sua actuação estava circunscrita ao espaço académico coimbrão "salvo quando o que estivesse em causa fosse a defesa da praxe” (apud Alves e Roldão, 1985-86: 13), durante a década de 1960, a clara imbricação entre um movimento estudantil em afluxo contestatário e as Repúblicas, enquanto lugar relevante deste processo, provoca uma rotação na concepção destes espaços e no tipo de práticas internas (Carreiro, 2004). Em lugar de focalizarem na sua vertente mais boémia e jocosa, as Repúblicas passam a autodefinir-se como "centros de formação cultural do estudante, agrupamentos regidos pelo princípio democrático da autogestão, gozando de independência económica e ideológica, libertas de qualquer género de tutela" (OB, 05-1966, s.n.). Nos símbolos das Repúblicas recém-criadas, a moca, a tesoura e a colher de pau, são substituídas por outro tipo de representações. Em 1972, o aparecimento da República Rosa Luxemburgo, casa estritamente feminina, rompendo desta forma com um universo até então exclusivamente confinado ao sexo masculino, mostra bem como estes espaços se encontram já distantes da imagem que possuíam uns anos antes.

Divergências quanto à estratégia proposta para a luta estudantil e o aprofundamento da crítica à "tradição académica" levam a uma cisão no seio do CR. Em comunicado datado de 28 de Novembro de 1970, três 
Repúblicas - Mil-Y-Onários, Trunfé-Kopos e Pim-Pim-Nelas - distanciam-se da estrutura, que consideram dominada por sectores reformistas que não põem "em causa as contradições sociais nas suas últimas consequências - a luta de classes" ("Requiem pelo Conselho de Repúblicas", 28-11-70). ${ }^{13}$ Se bem que as repúblicas não fossem já os "baluartes da praxe" de outrora, permaneciam ainda vinculadas a um certo imaginário que é objecto de nota irónica por parte dos signatários: "O que restará ao CR será conservar a sua faceta tradicionalista, imbuída de um certo casticismo de fados, copos de vinho, campeonatos de matrecos e suecas com um fundo negro de capas e batinas. Enfim abandonamos!..." ("Requiem pelo Conselho de Repúblicas", 28-11-70).

$\mathrm{Na}$ maioria dos organismos culturais põe-se em causa os princípios tradicionais de sociabilidade e moralidade. A capa e batina deixa de ter lugar nas apresentações ao vivo do Coro Misto e do CELUC, para "desilusão" da "burguesia” (R, 1973, 15306). As habituais práticas de integração são analisadas à luz dos novos valores dominantes. No início de 1972, a direcção do GEFAC, considerando que a inclusão se faz "pelo espírito, e não por manifestações que nada tem a ver com formalismos protocolares" propõe a abolição de uma pequena cerimónia apelidada de "baptismo", que consistia na escolha de um elemento do sexo oposto com quem se selava a entrada no grupo com um beijo. O colectivo justifica que agora era necessário pôr em causa "todo o carácter formal que tais manifestações traduziam" e abolir os "conceitos de privilégio e hierarquia de que enfermava a vida académica" (doc. manuscrito, GEFAC, 19-01-72).

Noutros organismos autónomos faz-se sentir a influência das vanguardas estéticas. No CAPC, realizam-se happenings que desafiam os conceitos tradicionais de arte e, colateralmente, de moralidade. No CITAC, o argentino Juan Carlos Oviedo começa a encenar, em 1970, a peça MacBeth... o que se passa na tua cabeça? que, após uma apresentação no Porto, estaria na base de um processo instaurado pelo Senado Universitário em virtude de alegadas ofensas à moral, levando ao encerramento do organismo. A direcção do CITAC viria a esclarecer que o espectáculo tinha sido produzido à margem do grupo ("CITAC esclarece”, CITAC, 09-06-70), provocando a eclosão, em Novembro de 1970, de um conflito estético-político no interior do próprio organismo, com um núcleo de

\footnotetext{
13 A 11 de Dezembro, a República Bamus-Ó-Bira subscreveria o comunicado da ruptura. A República Pim-Pim-Nelas, por seu lado, viria a esclarecer que a posição tinha sido indevidamente tomada por apenas alguns elementos da casa, posteriormente expulsos.
} 
sócios adeptos da Internacional Situacionista a demitir-se publicamente. Em comunicado, acusavam o grupo de ser "um travão aos tempos vivos (prazer, festa, imprevisto)" "“Tornar a vergonha ainda mais vergonhosa entregando-a à publicidade", Um grupo de sócios do CITAC que se demitem, s.d.).

A conflitualidade extravasa claramente para o terreno cultural. Factos como os incidentes em torno de uma peça de teatro da OTUC (Oficina de Teatro da Universidade de Coimbra) no Teatro Académico Gil Vicente, a 9 de Maio de 1970, a tentativa de reabilitação da Queima das Fitas em Maio de 1972, e o boicote ao Festival de Coros do Orfeon, em Abril de 1973, mostram bem esta proximidade. Aquando da tentativa de reabilitação da Queima das Fitas, por exemplo, um número significativo de estudantes entende boicotá-la, tecendo-lhe considerações fortemente críticas. Para os Núcleos Sindicais, a "Queima" era a "manifestação da ideologia burguesa no meio estudantil”, que não se distinguia, na essência, de um tipo de formação universitária que se pretendia combater, fazendo um paralelo entre "um ensino passivo, acrítico e autoritário" e a criação de um "tipo de estudante futuro e fiel cão-de-guarda do sistema” (s.t., NS, s.d.). Na mesma altura, a Comissão Associativa, constituída por vários organismos autónomos da AAC, condenava uma "festa toda voltada para si, como numa auto-contemplação totalmente abstraída duma realidade a que os estudantes já não eram alheios" ("Os reaccionários tiveram a 'Queima' que merecem”, CA, 17-05-72).

Numa reportagem publicada em 1973 no jornal República, Álvaro Guerra relatava uma Coimbra na qual o estudante perdera o seu "estatuto especial e passara a integrar-se de modo regular e discreto nas estruturas sociais da cidade, uma Coimbra sem capa e batina". Falando do desaparecimento da "polémica praxe" notava como "o romantismo exterior e folclórico representado por esse trajo negro se fora esbatendo, substituído pelos 'jeans', pela camisola e, à medida que a própria evolução urbanística da cidade ia rompendo o 'gheto' académico, escasseava a rapadela, sumiam-se fitas e grelo, laicizar-se-ia o trajar” (R, 1973, 15306). Já em 1970, a revista Capa e Batina se havia regozijado com o desaparecimento da praxe, aproveitando a ocasião para descrever pejorativamente a velha Coimbra, que "após as seis da tarde era apenas o reino dos doutores", com trupes que "calcorreavam as ruas da cidade" levando "consigo muitas vezes o chamado 'cão de fila', um caloiro que se prestava à tarefa de indicar aos 'doutores' os seus (dele) colegas” (CB, 1970, 35). 


\section{"Etnocídio" ou renovação?}

Analisando a comunidade académica coimbrã, António Rodrigues Lopes divide as contestações nela ocorridas entre "endógenas", isto é, provenientes da sociedade tradicional coimbrã, e "exógenas", que obedeceriam a "projectos estranhos à dinâmica tradicional". Conclui então que as movimentações estudantis dos anos sessenta "foram meros detalhes dum projecto mais vasto no contexto da 'contestação' de influência exógena", cujo ponto alto teria sido em 1969 com o "plano de captura do poder político da Sociedade Tradicional - a Praxe - promovendo em seguida o seu funcionamento em sentido inverso". Nesta linha de raciocínio, o movimento estudantil aparece como o agente de um plano de dissolução aparentemente anárquico mas bem montado, visando contaminar a pureza da comunidade académica com finalidades "artificiais" destinadas a provocar "um etnocídio" (Lopes, 1982: 242 e 320). Também António Nunes se faz eco desta leitura sacralizadora, entendendo as tentativas goradas de reposição da praxe durante a década de 1970 como resultado da incapacidade dos seus adeptos de fazer frente a grupos "perfeitamente organizados e senhores dos mecanismos de poder" (Nunes, 1989: 14).

À parte as intuições de natureza conspirativa e a obsessão com uma imagem essencialista da realidade em causa, existe algum fundamento em se considerar que durante a "crise de 1969" - e no período anterior se foi invertendo o sentido da praxe, se por essa inversão se entender a renovação anteriormente mencionada. No entanto, mais do que um coup d'État de sectores antitradicionalistas, a crítica e posterior abandono da praxe compreende-se como uma tomada de posição em sintonia com um novo ambiente emergente que se vinha desenhando desde finais da década de cinquenta. No troço final do regime, as práticas elitistas (em relação ao exterior) e hierárquicas (no seu interior), não se mostravam, de modo algum, harmonizáveis com os alicerces dos novos discursos igualitários que iam dominando o universo estudantil. Um elevado grau de politização, marcado pela irrupção dos mais variados matizes do marxismo enquanto referência macroexplicativa tornada dominante, acabaria por empurrar a praxe para um passado olhado como indesejável. Os estudantes já não se viam a si próprios como uma elite desligada da sociedade, confinada à cidade universitária e vivendo num mundo de tradições corporativas. A sua (auto-)imagem estava agora configurada de acordo com um direito a contestar as dinâmicas inerentes à Universidade, ao país e ao mundo e com um dever correlativo de intervenção e comprometimento social. 


\section{Referências bibliográficas}

Alves, Vítor; Roldão, Júlio (1985-86), “As Repúblicas - Lutas e lutos da Academia”, Via Latina, 13-15.

Andrade, Mário Saraiva de; Barros, Vítor Dias (1957), Código da Praxe Académica de Coimbra. Coimbra: Coimbra Editora.

Andrade, Mário Saraiva de (1959), Mataram um espantalho... Em defesa da praxe. Coimbra: Coimbra Editora.

Bebiano, Rui (2003), "Cidade e memória na intervenção estudantil em Coimbra”, Revista Crítica de Ciências Sociais, 66, 151-163.

Bebiano, Rui; Silva, Alexandra (2004), "A reidentificação do feminino e a polémica sobre a Carta a uma Jovem Portuguesa”, Revista de História das Ideias, 25, 423-454.

Benjamin, Walter (1995), "Tesi di Filosofia della Storia", in Angelus Novus. Saggi e frammenti. Torino: Einaudi, 75-86.

Boren, Mark Edelman (2001), Student Resistance. A History of the Unruly Subject. New York: Routledge.

Caiado, Nuno (1990), Movimentos estudantis em Portugal: 1945-1980. Lisboa: IED.

Cardina, Miguel (2008), A tradição da contestação. Resistência estudantil em Coimbra no Marcelismo. Coimbra: Angelus Novus.

Carreiro, Teresa (2004), Viver numa República de estudantes de Coimbra. Real República Palácio da Loucura, 1960-1970. Porto: Campo das Letras.

Cruzeiro, Celso (1989), Coimbra 1969: a crise académica, o debate de ideias e a prática ontem e hoje. Porto: Afrontamento.

Cruzeiro, Maria Eduarda (1979), "Costumes estudantis de Coimbra no século XIX: tradição e conservação institucional”, Análise Social, 15, 795-838.

Cruzeiro, Maria Eduarda (1985-86), "Questões de uma tradição", Via Latina, 23-27.

Cruzeiro, Maria Eduarda (1990), "Folclore estudantil e cerimonial académico: práticas de produção e reprodução institucional", Vértice, 28, 47-56.

Cruzeiro, Maria Manuela; Bebiano, Rui (orgs.) (2006), Anos inquietos. Vozes do movimento estudantil em Coimbra (1961-1974). Porto: Afrontamento.

Drago, Ana (2004), Agitar antes de ousar. O movimento estudantil "antipropinas". Porto: Afrontamento.

Duarte, Marta Benamor (1997), Foi apenas um começo: a crise académica de 1969 na história do movimento estudantil dos anos sessenta e da luta contra o Estado Novo. Lisboa: Faculdade de Ciências Sociais e Humanas da Universidade Nova de Lisboa (diss. de mestrado).

Estanque, Elísio; Bebiano, Rui (2007), Do activismo à indiferença. Movimentos estudantis em Coimbra. Lisboa: Imprensa de Ciências Sociais.

Frank, Robert (2000), "Imaginaire politique et figures symboliques internationales: Castro, Hô, Mao et le Che", in Geneviève Dreyfus-Armand et al. (orgs.), Les années 68. Le temps de la contestation. Paris: Complexe, 31-47. 
Frias, Aníbal (2003), "Praxe académica e culturas universitárias em Coimbra”, Revista Crítica de Ciências Sociais, 66, 81-116.

Garrido, Álvaro (1996), Movimento estudantil e crise do Estado Novo: Coimbra 1962. Coimbra: Minerva.

Gaudez, Pierre (1965), Os estudantes. Lisboa: O Tempo e o Modo/Moraes Editora. Hobsbawm, Eric; Ranger, Terence (1983), The Invention of Tradition. Cambridge: Cambridge UP.

Hobsbawm, Eric (2005), Tempos interessantes. Uma vida no século XX. Porto: Campo das Letras.

Lopes, António Rodrigues (1982), A sociedade tradicional coimbrã. Introdução ao estudo etnoantropológico. Coimbra.

Magnum Concilium Veteranorum, "Usos e costumes" (http://www.aac.uc.pt/mcv/ serv01.htm, acedido a 24 de Março de 2008).

Martins, Hermínio (2006), Classe, Status e Poder. Lisboa: Imprensa de Ciências Sociais.

Mellor, David Alan; Gervereau, Laurent (1997), The Sixties. Britain and France, 1960-1973. The Utopian Years. London: Philip Wilson.

Namorado, Rui (1989), "Para uma universidade nova: crónica da crise de 1969 em Coimbra”, Revista Crítica de Ciências Sociais, 27/28, 63-124.

Nunes, Adérito Sedas (2000), Antologia sociológica. Lisboa: Imprensa de Ciências Sociais.

Nunes, António (1989), “A sociedade tradicional académica e o mito do eterno retorno”, Munda, 18(14).

Nunes, António Manuel (2004), “As praxes académicas de Coimbra. Uma interpelação histórico-antropológica”, Cadernos do Noroeste, 22(1-2), 133-149.

Nunes, Mário (1996), "Alta de Coimbra - Candidata a Património Mundial”, Munda, 32, 3-16.

Peterson, Richard A. (1992), "La fabrication de l'authenticité: la country-music”, Actes de la Recherche en Sciences Sociales, 93, 3-19.

Prata, Manuel Alberto Carvalho (1993), "A praxe na Academia de Coimbra. Das práticas às representações”, Revista de História das Ideias, 15, 161-176.

Proença, Maria Cândida (org.) (1999), Maio de 1968 trinta anos depois. Movimentos estudantis em Portugal. Lisboa: Colibri.

Raposo, Eduardo (2000), O canto de intervenção (1960-1974). Lisboa: Biblioteca Museu República e Resistência.

Ribeiro, Rita Maria (2000), As lições dos aprendizes. As praxes académicas na Universidade do Minho. Braga: Universidade do Minho (diss. de mestrado).

Rouanet, Sérgio Paulo (1996), "A gramática do homicídio", in Michel Foucault et al., O bomem e o discurso. A arqueologia de Michel Foucault. Rio de Janeiro: Tempo Brasileiro, 91-139. 
Seabra, Jorge (2007), O cão andaluz. Santa Maria da Feira: Calendário de Letras.

Situação e Opinião dos Universitários. Inquérito promovido pelas Direcções-Gerais da Juventude Universitária Católica (1967). Direcção técnica e realização: CODES. Lisboa.

Vara, Flávio (1958), O espantalho da "praxe” coimbrã. Lisboa: Salesiana.

\section{Fundos documentais}

Centro de Documentação 25 de Abril - Pastas várias relativas ao Movimento Estudantil.

Museu Académico - Actas da Assembleia Magna da AAC (1955-1960).

\section{Publicações periódicas}

A Briosa (AB) - 1954-1959; Agora (AG) - 1961; Capa e Batina (CB) - 1965-1972; Diário de Lisboa (DL) - 1957-1974; Estudos (E) - 1967; O Badalo (OB) - 1966-1968; OSéculo (S) - 1957-1958; República (R) - 1958-1973; Tabu, Revista do Sol (T) - 2006; Via Latina (VL) - 1956-1962. 